\title{
Histamine stimulates the proliferation of human articular chondrocytes in vitro and is expressed by chondrocytes in osteoarthritic cartilage
}

\author{
L C Tetlow, D E Woolley
}

Ann Rheum Dis 2003;62:991-994

Objectives: To determine the effects of histamine on the proliferative rate of human articular chondrocytes (HAC) in vitro, and to demonstrate whether HAC in osteoarthritic (OA) cartilage express histamine and histidine decarboxylase (HDC)

Methods: HAC in vitro were incubated with and without histamine in 96 well culture plates and the extent of cell proliferation was determined using the naphthol blue-black method. Histamine effects were analysed with the histamine $\mathrm{H}_{1}$ and $\mathrm{H}_{2}$ receptor antagonists, mepyramine and ranitidine, respectively. Rabbit polyclonal antibodies and alkaline phosphatase conjugated secondary antibodies were used, and histamine and HDC were demonstrated by immunohistochemistry in $\mathrm{OA}$ cartilage tissues.

Results: Histamine stimulated the proliferation of HAC in culture. This stimulation was blocked by the addition of mepyramine, but not ranitidine, suggesting that the effect is mediated through $\mathrm{H}_{1}$ histamine receptors. The addition of $\alpha$-fluoromethylhistidine, a specific inhibitor of histidine decarboxylase (the enzyme responsible for histamine production), reduced the rate of proliferation of HAC. Both histamine and histidine decarboxylase were demonstrated in chondrocytes of OA cartilage by immunohistochemistry. Conclusion: Changes induced by histamine in the proliferative rate of HAC may contribute to the formation of chondrocyte clusters associated with OA cartilage; an observation supported by the demonstration of histamine and HDC expression by chondrocytes of OA cartilage in situ.

$\mathrm{D}$ egeneration of articular cartilage and the appearance of chondrocyte clusters are characteristic features of osteoarthritis (OA), and although biomechanical and genetic factors may be implicated, the pathogenesis of OA remains unknown..$^{1-3}$ Several factors may regulate the hyperactive nature of OA chondrocytes, but recent studies of our group have indicated that histamine contributes to their "degenerative" or " catabolic" behaviour, at least in in vitro experiments..$^{4-6}$

Histamine has a recognised role in allergic and inflammatory reactions and is an important modulator of numerous physiological processes, including cell proliferation, angiogenesis, and vasopermeability. ${ }^{7}$ Histamine is reported to modify the behaviour of many cell types in vitro, including chondrocytes, fibroblasts, macrophages, epithelial cells, endothelial cells, and T cells. Histamine also modulates the production of many cytokines and the expression of their receptors. ${ }^{8}$ Histamine regulates cellular processes through the expression of histamine receptors. ${ }^{9} \mathrm{H}_{1}$ and $\mathrm{H}_{2}$ receptors are known to be located in variable numbers and ratios on the plasma membranes of target cells; $\mathrm{H}_{3}$ and $\mathrm{H}_{4}$ receptors have been reported in neuronal tissues and in human leucocytes, respectively. We have previously shown that $\mathrm{H}_{1}$ and $\mathrm{H}_{2}$ histamine receptors are expressed by human articular chondrocytes (HAC); stimulation of the $\mathrm{H}_{1}$ receptors resulted in increased prostaglandin $\mathrm{E}_{2}\left(\mathrm{PGE}_{2}\right)$ production, whereas stimulation of the $\mathrm{H}_{2}$ receptors resulted in increased cAMP. ${ }^{5}$ More recently we have reported that histamine stimulates the production of matrix metalloproteinases (MMPs)-13 and -3 (collagenase 3 and stromelysin-1, respectively) by HAC in vitro, ${ }^{6}$ enzymes known to play a part in matrix degradation and produced by

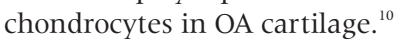

Mast cells (MCs) are recognised as a prime source of histamine, which is released in response to factors such as cytokines, activated complement, and physical or traumatic stimuli. ${ }^{11}$ MCs and raised levels of histamine are present in a significant proportion of synovial fluids from patients with OA. ${ }^{12}$ The synthesis of histamine from histidine is catalysed by histidine decarboxylase (HDC), an enzyme characteristically expressed by MCs and basophils, but more recently demonstrated in monocyte-macrophages, neurones, and some tumour cells. ${ }^{13}$

Here we report the effect of histamine on the proliferative rate of HAC in vitro, and demonstrate by immunolocalisation the presence of both histidine decarboxylase and histamine in human chondrocytes of OA cartilage.

\section{METHODS}

\section{Cell culture}

HAC were isolated from cartilage from OA tissues removed at joint replacement surgery, as described previously. ${ }^{4}$ Patient consent and ethical approval were obtained for all the tissues used in this study. All cultures were of a chondrocytic phenotype as shown by positive S100 and type II collagen immunostaining as demonstrated previously. ${ }^{10}$ HAC were grown to confluence in $80 \mathrm{~cm}^{2}$ culture flasks in Dulbecco's modified Eagle's medium (DMEM) $+10 \%$ fetal calf serum (FCS). At first or second passage, cells were seeded into 96 well culture plates, at densities of approximately $2 \times 10^{3}$ cells/well. After 24 hours the cells were treated with either DMEM $+2 \%$ FCS alone (control), or DMEM $+2 \%$ FCS plus histamine (Sigma, Poole, UK) range $1-100 \mu \mathrm{mol} / \mathrm{l}$ (minimum of eight wells for each treatment). The medium with or without histamine was replenished every 48 hours, and after six days cell growth was estimated. In further experiments the specific $\mathrm{H}_{1}$ and $\mathrm{H}_{2}$ histamine receptor antagonists, mepyramine and ranitidine

Abbreviations: DMEM, Dulbecco's modified Eagle's medium; EDAC, 1-ethyl-3-(3-dimethylaminopropyl) carbodiimide; FCS, fetal calf serum; $\alpha-\mathrm{FMH}, \alpha$-fluoromethylhistidine; HAC, human articular chondrocytes; HDC, histidine decarboxylase; MCs, mast cells; MMP, matrix metalloproteinase; $\mathrm{OA}$, osteoarthritis; $\mathrm{PGE}_{2}$, prostaglandin $\mathrm{E}_{2}$ 
A
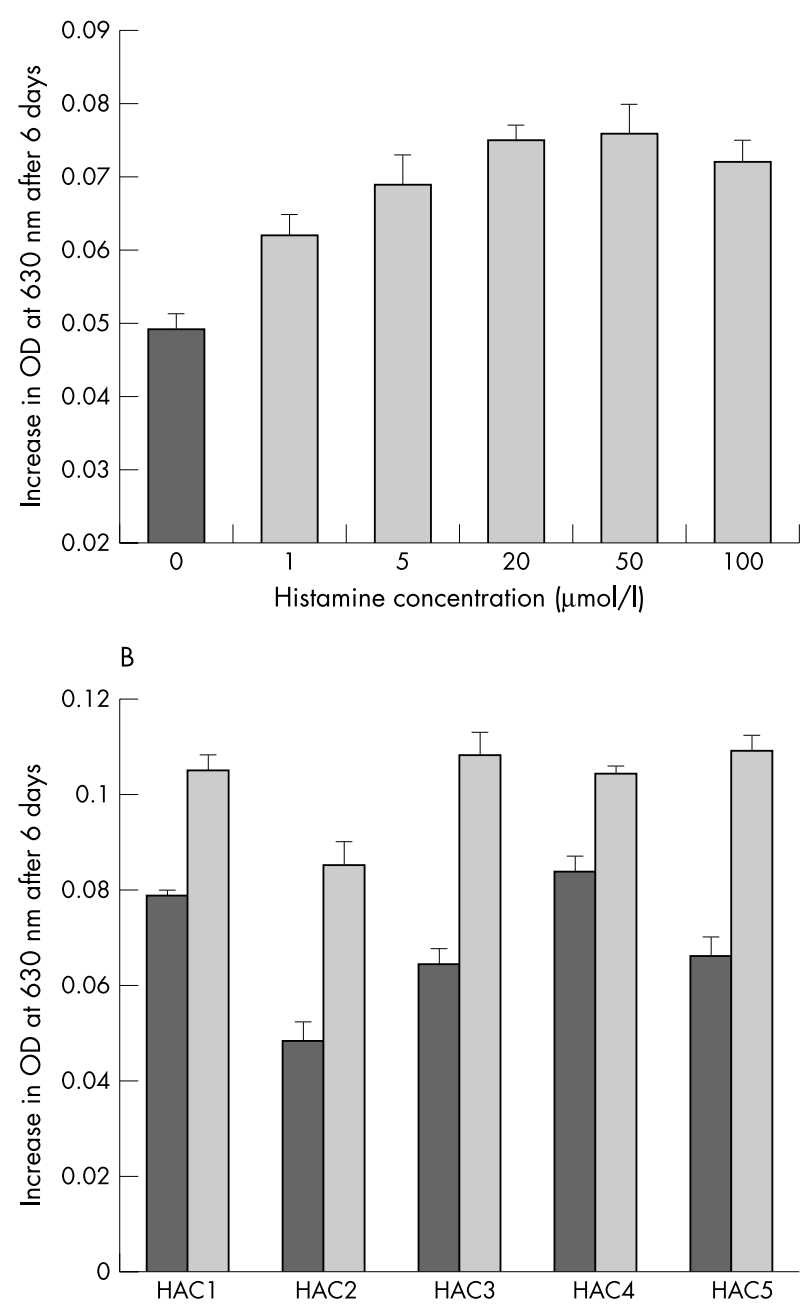

C

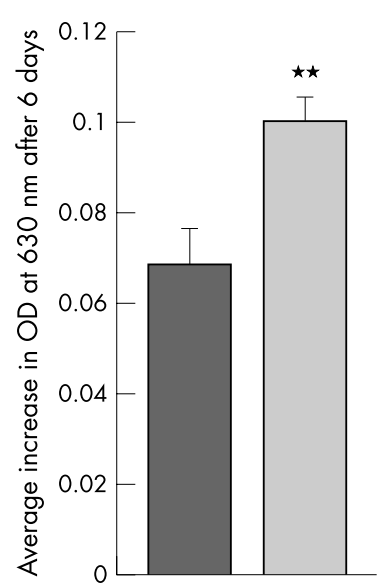

Figure 1 Effect of histamine on the proliferative rate of $\mathrm{HAC}$ in vitro. (A) Effect of different histamine concentrations (1-100 $\mathrm{mmol} / \mathrm{l})$ on cell proliferation after six days. Preparation HAC2, passage 2 . Data represent intra-assay values, showing mean (SEM) of eight wells for each treatment. (B) Effect of histamine $(20$ umol/l) on cell proliferation of five different HAC cultures after six days. Data represent intra-assay values, showing mean (SEM) of eight wells for each treatment. (C) Averaged data from five HAC cultures with or without histamine $(20 \mu \mathrm{mol} / \mathrm{I})$. Data represent the mean (SEM) of the five HAC cultures presented in (B). ${ }^{* *} p=0.00012$, Student's $t$ test.

(both from Sigma, UK), respectively, were added at a concentration of $20 \mu \mathrm{mol} / \mathrm{l},{ }^{56}$ together with histamine at the optimal
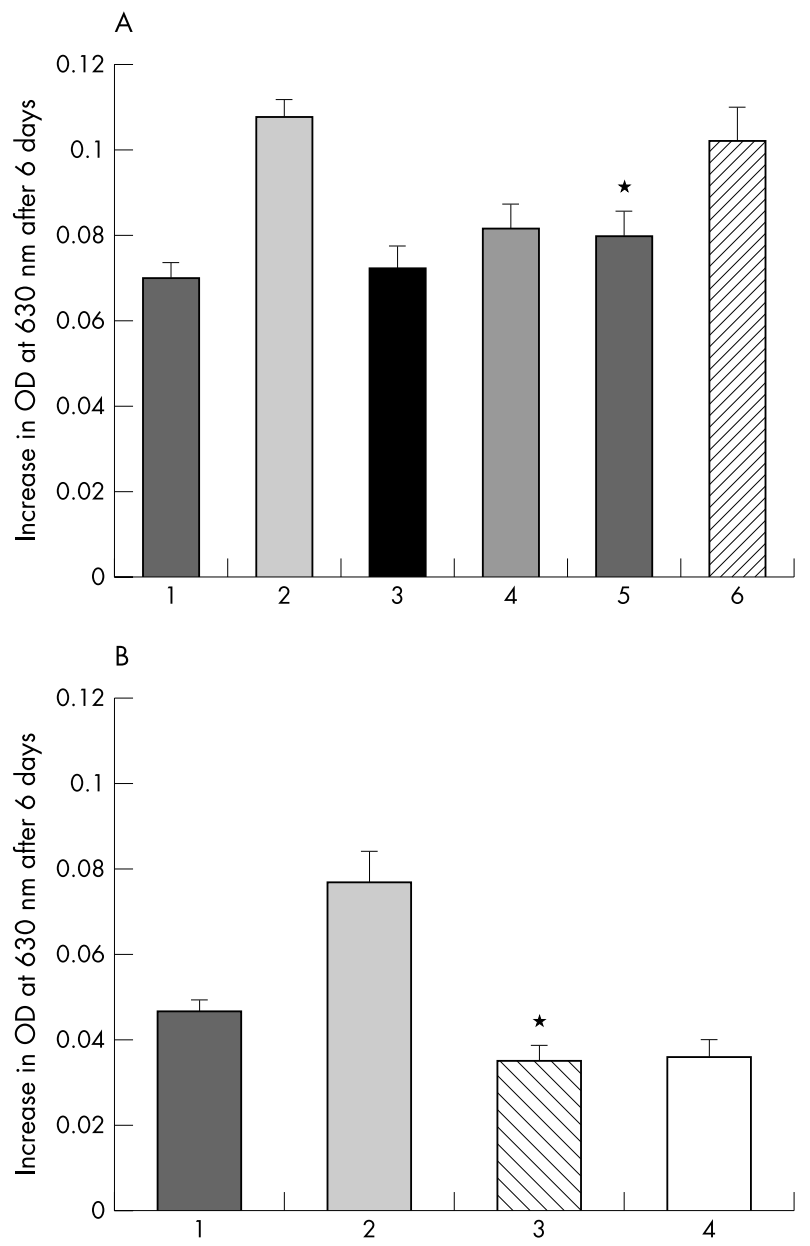

Figure 2 (A) Effect of specific $\mathrm{H}_{1}$ and $\mathrm{H}_{2}$ histamine receptor antagonists on the histamine stimulated proliferation of HAC. 1, Control culture; 2 , histamine $(20 \mathrm{\mu mol} / \mathrm{l}) ; 3,+$ mepyramine $(20$ pmol/l $) ; 4,+$ ranitidine $(20 \mu \mathrm{mol} / \mathrm{l}) ; 5,+$ histamine $(20 \mathrm{\mu mol} / \mathrm{l})$ and mepyramine $(20 \mu \mathrm{mol} / \mathrm{l}) ; 6$, + histamine $(20 \mu \mathrm{mol} / \mathrm{l})$ and ranitidine $(20 \mu \mathrm{mol} / \mathrm{l})$. Note the significant inhibition of the histamine effect by mepyramine ( ${ }^{*} p=0.003$, Student's $t$ test). Representative experiment $(n=3)$ using preparation $\mathrm{HAC} 3$, passage 2 , this being qualitatively similar for HAC2 and 5. (B) Effect of $\alpha-F M H$ on the proliferation of HAC. 1, Control culture; $2,+$ histamine $(20 \mu \mathrm{mol} / \mathrm{l}) ; 3,+\alpha-\mathrm{FMH}$ $(100 \mu \mathrm{mol} / \mathrm{l}) ; 4,+\alpha-\mathrm{FMH}(100 \mu \mathrm{mol} / \mathrm{l})$ and mepyramine $(20$ $\mu \mathrm{mol} / \mathrm{l})$. Representative experiment showing qualitatively similar data from two HAC cultures. Note modest reduction in proliferative rate of HAC by $\alpha$-FMH ( ${ }^{*} p=0.05$, Student's $t$ test).

concentration $(20 \mu \mathrm{mol} / \mathrm{l})$. To assess whether HAC might synthesise their own histamine, cultures were treated with $\alpha$-fluoromethylhistidine $(\alpha-\mathrm{FMH}$, an inhibitor of histamine synthesis, $100 \mu \mathrm{mol} / \mathrm{l}$, Sigma, $\left.\mathrm{UK}^{14}\right)$.

\section{Cell proliferation estimation}

Cell numbers were estimated by the naphthol blue-black (NBB) method according to Vilcek et al. ${ }^{15}$ The method has previously been standardised for human chondrocytes and cell numbers were shown to be proportional to optical density at $630 \mathrm{~nm}$. For each experiment eight wells were seeded with cells at similar densities in a separate plate which was used as a starting value - that is, an NBB test performed immediately after the 24 hour settling period. This value was subtracted from those obtained after six days for the treated and untreated wells.

\section{Immunolocalisation of HDC and histamine in OA cartilage}

Specimens of cartilage from OA joints $(n=9)$ were fixed in l-ethyl-3-(3-dimethylaminopropyl) carbodiimide (EDAC; 

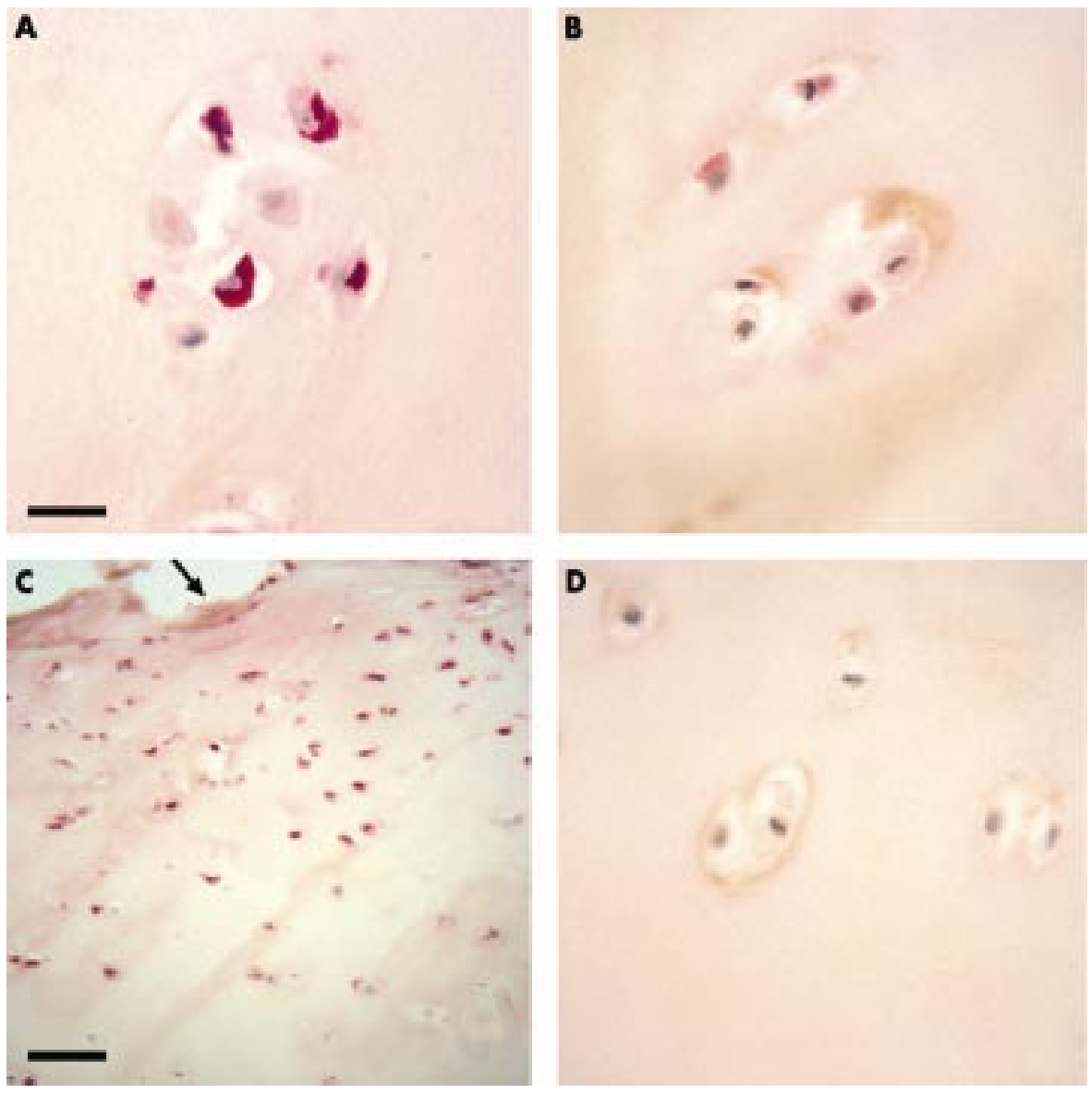

Figure 3 Immunolocalisation of histamine and histidine decarboxylase in chondrocytes of OA cartilage. (A) Tissue section of OA cartilage showing a proportion of the cells in a chondrocyte cluster positive for histamine (red). (B) Tissue section of OA cartilage with a proportion of cells of a chondrocyte cluster immunostained for HDC (red). (C) Low power micrograph of tissue section of OA cartilage showing histamine expression by HAC predominantly in the superficial articular surface (arrowed), and not in the deeper regions of the articular cartilage. (D) Control tissue section with normal rabbit lgG as substitute for primary antibodies showing no immunostaining. Bar $=25 \mu \mathrm{m}$ for micrographs $\mathrm{A}$, B, and D; bar $=140 \mu \mathrm{m}$ for micrograph C. All sections were lightly counterstained with Harris's haematoxylin.

Sigma, UK) or $4 \%$ buffered formalin and processed to paraffin wax. Histamine was demonstrated in EDAC fixed $5 \mu \mathrm{m}$ tissue sections using rabbit polyclonal antihistamine (Chemicon, UK; diluted 1:200) and detected and visualised by alkaline phosphatase conjugated biotin/streptavidin (AP-ABC; DAKO, UK), which gives a red colour, as described previously. ${ }^{10}$ HDC was demonstrated in $5 \mu \mathrm{m}$ formalin fixed tissue sections after a pronase antigen retrieval step. Primary antibody was rabbit polyclonal antihuman HDC (EuroDiagnostica; diluted 1:1000) followed by the AP-ABC detection system described above.

\section{RESULTS}

\section{Proliferation studies}

The proliferative rate of HAC was significantly stimulated (15-45\% above control) when the cells were treated with various concentrations of histamine over six days. This was maximal at approximately $20 \mu \mathrm{M}$ histamine (fig 1A). Although the extent of stimulation of proliferative rate varied between different HAC cultures (fig 1B), the increase in cell numbers of histamine-treated cells relative to controls was found to be significantly different (fig $1 \mathrm{C}, \mathrm{p}=0.00012$ ). Histamine stimulation of HAC proliferation was inhibited by the $\mathrm{H}_{1}$ histamine receptor antagonist, mepyramine, but not by the $\mathrm{H}_{2}$ histamine receptor antagonist, ranitidine (fig 2A). Addition of $\alpha-F M H$, which inhibits the synthesis of histamine, either alone or together with mepyramine, reduced the proliferation of HAC to below that of control values (fig $2 \mathrm{~B}$ ).

\section{Immunolocalisation of HDC and histamine}

A variable proportion of chondrocytes within each OA cartilage specimen, either those in single or enlarged lacunae of chondrocytes clusters, were shown to be positive for histamine and HDC (figs 3A and B, respectively); all staining appeared to be intracellular. For both antigens the strongly positive cells were found usually, but not exclusively, in the superficial zone adjacent to the articular surface. Figure 3C illustrates this for the localised distribution of histamine. Cells deeper within the OA cartilage specimens were more often negative or weakly stained, as were the four specimens of normal cartilage examined for HDC expression (data not shown). Interestingly, both positively stained and negative cells were seen within the same enlarged lacunae of OA chondrocyte clusters. OA cartilage tissue sections receiving phosphate buffered saline or non-immune rabbit IgG in place of the primary antibodies showed no immunostaining (fig 3D).

\section{DISCUSSION}

Histamine is a recognised feature of various allergic conditions and for many years its importance was limited to that field. With the more recent realisation that histamine is produced by cells other than MCs and basophils, and is recognised as a contributory factor in inflammatory disorders, tumour cell growth/transformation, and neurotransmission, its potential to modify the behaviour of other cells, such as chondrocytes, has become apparent. 
Advanced OA cartilage is characterised by such common features as fibrillations, matrix depletion, and the formation of chondrocytic cell clusters. ${ }^{12}$ MMPs are strongly implicated as mediators of the intrinsic degenerative changes consistent with this pathology, and several MMPs have been demonstrated in HAC of late stage OA. ${ }^{10}$ Our recent studies have demonstrated an increase in both MMP-13 (collagenase 3) and MMP-3 (stromelysin-1) production by HAC in vitro when stimulated with histamine, ${ }^{6}$ and $\mathrm{PGE}_{2}$ production was similarly enhanced. ${ }^{4}$

Because histamine stimulates the proliferative rate of several cell types it seemed plausible that human chondrocytes, known to express both $\mathrm{H}_{1}$ and $\mathrm{H}_{2}$ histamine receptors and to be hyperproliferative in OA, might also respond in a similar manner to histamine exposure. The current study has indeed demonstrated a mitogenic effect on HAC. Because this proliferative stimulation of HAC was antagonised by mepyramine, it would appear that this effect is mediated through the $\mathrm{H}_{1}$ histamine receptor pathway.

We have previously shown that interleukin $1 \beta$ and tumour necrosis factor $\alpha$ are synthesised by HAC in OA cartilage ${ }^{10}$ and also in cartilage of the rheumatoid lesion, ${ }^{16}$ possibly providing autocrine factors for MMP and $\mathrm{PGE}_{2}$ production, and the inhibition of matrix synthesis. Interestingly, histamine is reported to be a modulator of cytokine production, ${ }^{8}$ especially the interleukin 18 cytokine cascade, which in turn may play a part in the stimulation of histamine synthesis. ${ }^{17}$

There are several reports of raised histamine levels in OA synovial fluids. ${ }^{12}$ Until now activated MCs were presumed to be the major source of histamine in arthritic joints; but the observations reported here of histamine and HDC expression by HAC in OA cartilage demonstrates HAC as a potential source of this potent amine. This finding has several implications for the catabolic activity of $\mathrm{HAC}$ in degenerative cartilage, although the sequence of events for histamine: cytokine:proteinase:prostaglandin expression remains to be elucidated. Data from in vitro HAC experiments using $\alpha-F M H$ showed that proliferation of the cells was inhibited to some extent, suggesting that HAC derived histamine may contribute to the chondrocyte growth rate in vitro. In summary, the histamine-induced increase in proliferative rate of HAC in vitro, the demonstration by immunohistochemistry of histamine and HDC within HAC of OA cartilage, and earlier studies, ${ }^{4-6}$ strongly suggest that histamine:chondrocyte interactions may contribute to the degenerative changes associated with OA cartilage.

\section{ACKNOWLEDGEMENTS}

This work was supported by the PPP Foundation. We thank orthopaedic surgeons Mr T Dunningham (Tameside Hospital, Manchester), Mr M Morris, and Mr DS Johnson (both of Stepping Hill Hospital, Stockport) for the supply of surgical specimens. We also thank the Department of Medical Illustration, Manchester Royal Infirmary, for help with colour figures.

\section{Authors' affiliations}

L C Tetlow, D E Woolley, University Department of Medicine,

Manchester Royal Infirmary, Oxford Road, Manchester, M13 9WL, UK

Correspondence to: Dr L C Tetlow; lynne.c.tetlow@man.ac.uk

Accepted 5 March 2003

\section{REFERENCES}

1 Howell DS, Pelletier J-P. Etiopathogenesis of osteoarthritis. In: McCarty DJ, Koopman WJ, eds. Arthritis and allied conditions: a textbook of rheumatology. Vol 2. 12th ed. Philadelphia: Lea \& Febiger, 1993: 1723-34.

2 Poole AR. Cartilage in health and disease. In: McCarty DJ, Koopman WJ, eds. Arthritis and allied conditions: a textbook of rheumatology. Vol 2. 12th ed. Philadelphia: Lea \& Febiger, 1993:279-333.

3 Goldring MB. The role of the chondrocyte in osteoarthritis. Arthritis Rheum 2000;43:1916-26.

4 Taylor DJ, Yoffe JR, Brown DM, Woolley DE. Histamine stimulates prostaglandin-E production by rheumatoid synovial cells and human articular chondrocytes in culture. Arthritis Rheum, 1986;29:160-6.

5 Taylor DJ, Woolley DE. Evidence for both histamine $\mathrm{H}-1$ and $\mathrm{H}-2$ receptors on human articular chondrocytes. Ann Rheum Dis 1987;46:431-5.

6 Tetlow LC, Woolley DE. Histamine stimulates matrix metalloproteinase-3 and -13 production by human articular chondrocytes in vitro.Ann Rheum Dis 2002;61:737-40.

7 White MV, Kaliner MA. Histamine. In: Gallin Jl, Goldstein IM, Snyderman R, eds. Inflammation: basic Principles and clinical correlates. New York: Raven Press, 1988:169-93.

8 Falus A, Meretey K. Histamine - an early messenger in inflammatory and immune reactions. Immunol Today 1992;13:154-6.

9 Leurs R, Timmerman H. Histamine receptors. 2000; http:// www.tocris.com/histamine.htm

10 Tetlow LC, Adlam DJ, Woolley DE. Matrix metalloproteinase and proinflammatory cytokine production by chondrocytes of human osteoarthritic cartilage - associations with degenerative changes. Arthritis Rheum 2001;44:585-94.

11 Keiner HP, Baghestanian M, Dominikus M, Waklschofer S, Ghannadan $M$, Willheim $M$, et al. Expression of the C5a receptor (CD88) on synovial mast cells in patients with rheumatoid arthritis. Arthritis Rheum 1998;41:233-45

12 Malone DG, Irani AM, Schwartz LB, Barrett KE, Metcalfe DD. Mast cell numbers and histamine levels in synovial-fluids from patients with diverse arthritides. Arthritis Rheum 1986;29:956-63.

13 Laszlo V, Rothe G, Hegyesi H, Szeberenyi JB, Orso E, Schmitz G, et al. Increased histidine decarboxylase expression during in vitro monocyte maturation: a possible role of endogenously synthesised histamine in monocyte/macrophage differentiation. Inflammation Res 2001:428-34.

14 Woldemussie E, Beaven P. $\alpha$-Fluoromethylhistidine. Kinetics of uptake and inhibition of histamine synthesis in basophil $(2 \mathrm{H} 3)$ cell cultures. Mol Pharmacol 1985;28:191-9.

15 Vilcek J, Palombella VJ, Henriksen-De SD. Fibroblast growth-enhancing activity of tumour necrosis factor and its relationship to other polypeptide growth factors. J Exp Med 1986; 163:632-6.

16 Tetlow LC, Woolley DE. Mast cells, cytokines and metalloproteinases at the rheumatoid lesion - dual immunolocalisation studies. Ann Rheum Dis 1995;54:896-903

17 Yamaguchi K, Motegi K, Kurimoto M, Endo Y. Induction of the activity of histamine-forming enzyme, histidine decarboxylase, in mice by IL-18 and by IL-1 8 plus IL-12. Inflammation Res 2000;49:513-19. 